\title{
ECTOMYCORRHIZAL MACROFUNGI IN THE VICINITY OF Grand Teton AND Yellowstone National PARKS
}

\author{
KENT H. MCKNIGHT \\ DEPARTMENT OF BOTANY AND RANGE SCIENCE \\ BRIGHAM YOUNG UNIVERSITY $\downarrow$ PROVO
}

\section{$\downarrow \quad$ INTRODUCTION}

Fieldwork on this project in 1996 concentrated again on the primary long-term objective of adding to the species inventory and associated data of the broad area previously defined (McKnight, K.H. and M. Moser, 1993), using the same collecting, laboratory, and herbarium methods. Our studies again concentrated on the genus Cortinarius. Our chief concern during the short period of field work this summer was directed toward obtaining additional data, particularly illustrations, for species we had found previously in the vicinity of the parks.

\section{$\downarrow \quad$ DATA}

Although the weather was mostly unfavorable for mushroom fruiting we were remarkably successful, largely resulting from our knowledge of favorable collecting areas gained over many years of study in the Parks and surrounding areas. This is highly significant inasmuch as many mushroom species fruit at very irregular, often widely separated intervals. A good example is Lactarius olympianus Hesler \& A.H. Smith (1979) which we collected at Lake Butte in 1964 and which we had not seen in the area since then until 1994 (although Hesler \& Smith reported one collection from Wyoming and many collections from northern Idaho, Colorado, and Washington). Our 1964 and 1994 material was not satisfactory for illustration.
This summer (1996) we found this species in excellent condition at Sand Point on the West side of Yellowstone Lake (Fig. 1). Superficially, it may be confused in the field with $L$. deliciosus (Fries) S.F. Gray var. deliciosus which we also illustrated from collections made in Wyoming this summer (Fig. 2), and from material collected in Florenville, Belgium on November 3, 1975 (Fig. 3). Our illustrations show subtle but significant differences in the orange colors of fresh specimens of the two taxa as described by Hesler and Smith (1979).

Other collections from the same Wyoming locality appear to be Cortinarius delibutus Fries and a similar, perhaps undescribed species, both of which need additional study to further strengthen species concepts.

From Turpin Meadows, outside the Parks, we also found and illustrated Cortinarius laniger Fries, C. umbilicatus Karsten, Lactarius scrobiculatus (Scop. ex Fries) Persoon, L. deliciosus Fries, and a questionable Cortinarius caninus. All of these are significant records of visual data which are essential in mushroom taxonomy.

\section{$\downarrow \quad$ LITERATURE CITED}

Hesler, L.R. and A.H. Smith. 1979. North American species of Lactarius. Ann Arbor, Michigan. 841 pp. 
McKnight, K.H. and M.M. Moser. Taxonomy and Ecology of Ectomycorrhizal Macrofungi in the Vicinity of Grand Teton and Yellowstone National Parks. In Univ. of Wyo. Nat'l. Park Serv. Res. Ctr. 17th Ann. Rept., 1993. pp. 77-80.

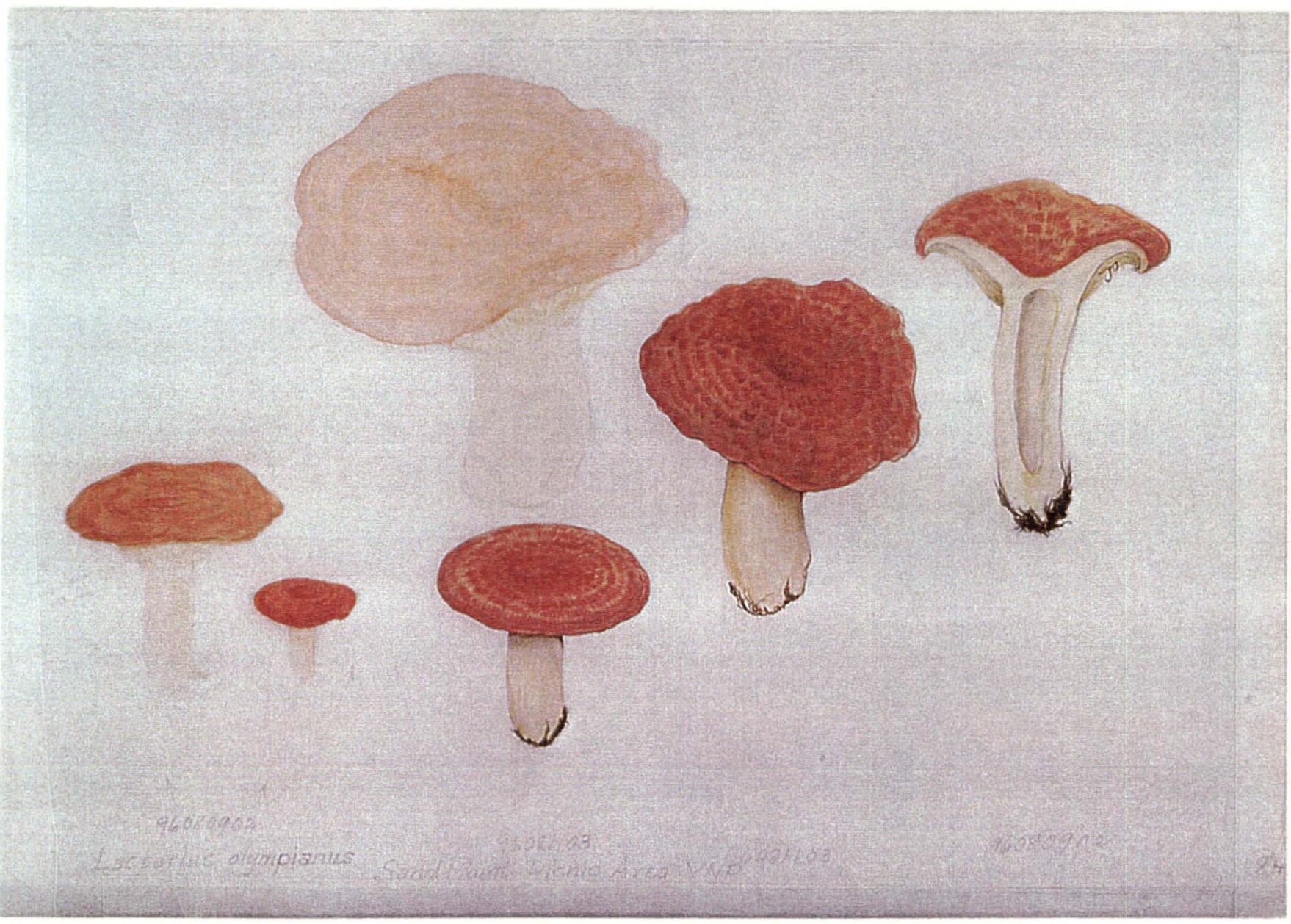




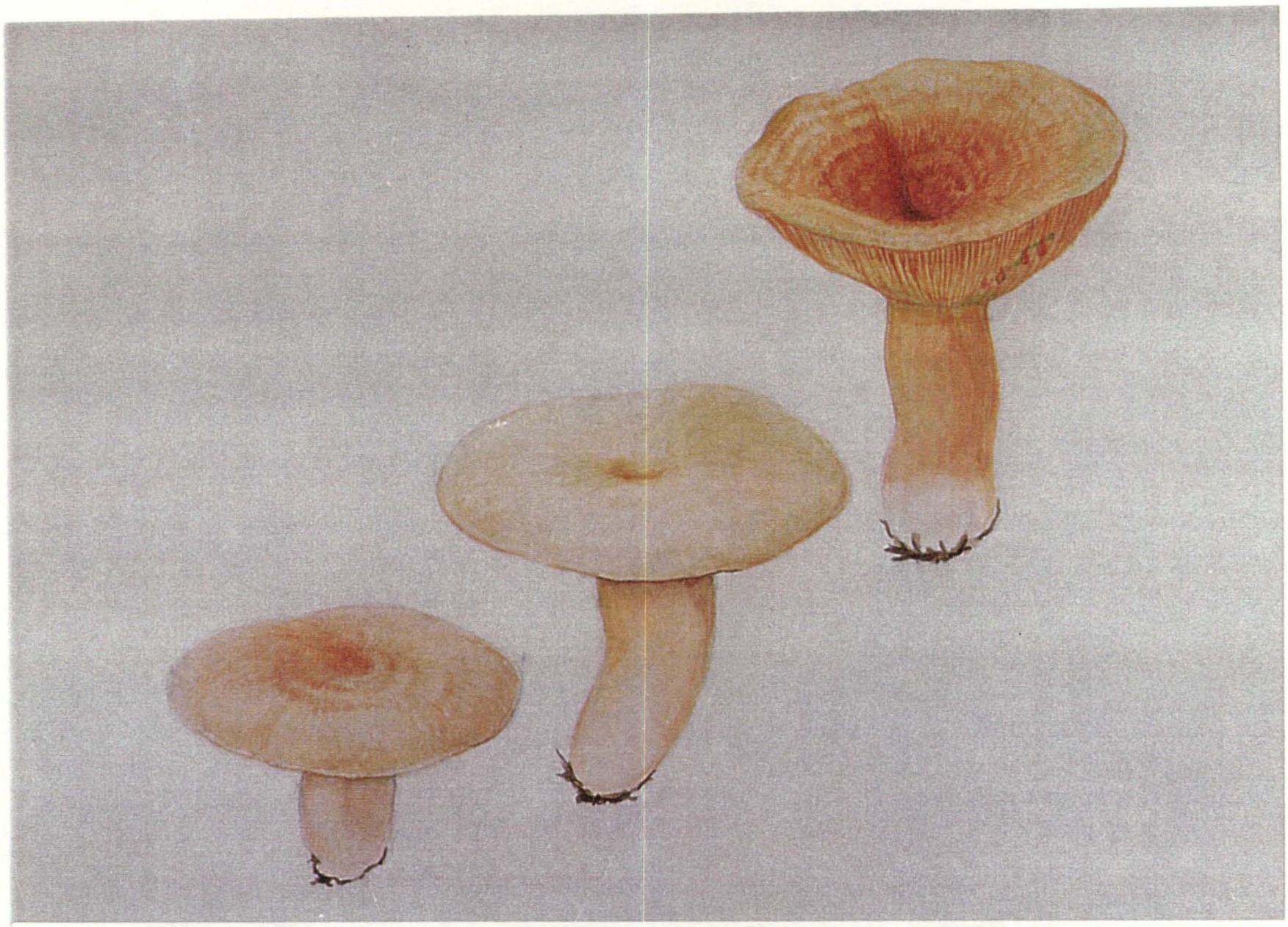

